\title{
Successful Performance Measurement in SMEs through Personnel Participation
}

\author{
Janne Sinisammal, Pekka Belt, Janne Harkonen, Matti Mottonen, Seppo Vayrynen
}

University of Oulu, Oulu, Finland.

Email: \{janne.sinisammal, pekka.belt, janne.harkonen, matti.mottonen, seppo.vayrynen\}@oulu.fi

Received December $5^{\text {th }}, 2011$; revised January $9^{\text {th }}$, 2012; accepted January $20^{\text {th }}, 2012$

\begin{abstract}
Balanced scorecard has proven to be a functional tool for large companies, however, small- and medium-sized enterprises (SME) have experienced it too complicated for their purposes. The aim of this research is to analyse the potential of simplifying balanced scorecard in order to acknowledge the practical realities of SMEs. The results of this study indicate that the viewpoints covered by balanced scorecard can be simplified into three categories of productivity, work fluency, and safety. A simplified balanced scorecard can act as a tool for internal communication in SMEs, by converting company strategy into common terms understandable by the employees. The managers of SMEs can use the results of this study as an example when considering the implementation of their business strategy. It is vital to involve employees when developing performance indicators.
\end{abstract}

Keywords: Performance Indicator; Balanced Scorecard; Employee Participation; Internal Communication; Critical Success Factor; Working Life; SME

\section{Introduction}

Feedback concerning work has a purpose of guiding the work process in a manner that an organisation will better reach its goals [1,2]. In order for this feedback to be effective, it must be based on some kind of performance assessment. In the early 1900s work was measured and optimised based on the accuracy of the work movement of an individual factory employee [3]. After the Second World War, the focus of evaluating work moved towards assessing the results of work groups instead of individuals [4]. Towards the end of 1900 s assessing work was extended from production factors to other parts of organisations, and also outside the organisations along supply chains. Assessing performance was joined with strategic goals, while the number of indicators was increased simultaneously along with needs to improve quality and flexibility [5].

Assessing the performance of a work group, for example production line personnel, may be limited to a single theme such as safety, or order and cleanliness [6-11]. From the perspective of management, useful information can be collected by focusing indicators to those areas of an organisation that have the greatest impact on reaching goals. This way, assessing performance will focus on the organisation's critical success factors and combining strategy and operational activities becomes one of the main goals of performance assessment [12].
When designing performance indicators, it is seen vital that data is easily available, the indicators are reliable, accurate, accepted among employees, easily understandable, economic, and that the feedback is swift $[13,14]$. It is also seen that the performance indicators must complement company's strategic goals, while partial optimisation and a large number of indicators is avoided [15]. Performance indicators are tied to time and place and they are not directly transferrable from a company to another, and must be reconsidered when the business environment evolves [16]. Nowadays, in maybe one of the most wide utilised performance measurement system, balanced scorecard (BSC), the object of measurement are divided into four groups of factors: customer factors, internal process factors, and the factors of learning and growth $[17,18]$. This division into four groups has an aim of ensuring that assessment is equally focused to all those factors that have an impact on company's success.

According to [19] balanced scorecard is more suitable as a means for top management to obtain a general overview of company situation, rather than being a tool for operational management. Fundamentally, balanced scorecard is seen to be more a monitoring than a development tool. It is also emphasised that the object of measurement described in the balanced scorecard should not be accepted as they are, but the applicability of each indicator ought to be considered individually to be suitable for 
each company's vision and strategy [20,21].

Balance scorecard's aim to limit the number of measurement objects is seen as a good trend, while tangible guidelines for implementation are experienced to be missing [15]. Some literature, however, describes goal setting for performance indicators and the phases of design and implementation, while practical aspects of defining indicators, especially the employee participation are less discussed [20,22,23].

Researchers, especially those of Anglo-Saxon origin, almost completely disregard the employee role in developing performance indicators. However, [24] see the employee participation as an important issue. Employee participation in workplace development projects may improve personnel relations, professional know-how, and commitment to new ways, among any other potential benefits [25]. Participating in building performance indicators may enable personnel to better understand their own role as a part of whole [26].

One of the potential weaknesses of balances scorecard is seen it being originally developed for the needs of large North American companies, where the organisational culture and working environment are somewhat different than those of European and Asian Companies [21,27].

This research has an aim of clarifying how balanced scorecard could be simplified in order it to better fit the purposes of small and medium sized enterprises (SME). Another goal is to find out which practical aspects must be acknowledged while building performance indicators. In practice, this study is realised by analysing the workplace specific success factors of six different organisations and by conducting semi-structured interviews. Success factors are formulated into performance indicators and they are set clear goals. The above described can be condensed into the following research question:

How can balanced scorecard be simplified, and what are the practical aspects that must be acknowledged, in order to better serve the needs of small and medium sized companies?

\section{Literature Review}

Balanced Scorecard is a performance measurement system developed on the principles of goal oriented operations management [28]. Balanced scorecard was developed for the need to complement short-term economic indicators with performance indicators describing changes in intangible assets. Focusing solely on economic indicators was seen to weaken the realisation of long-term goals [29]. Organisation's intangible assets constitute of personnel know-how and work motivation, functional management systems and organisation's interest group relations, among others [30].
[31] views the development of balanced scorecard to contain three phases. The first generation performance indicators were simplified and contained four viewpoints, covering learning, growth, company internal processes, and customer viewpoint, aside economic the viewpoint [12]. The first generation balanced scorecard emphasised the interaction of these four viewpoints. Selecting indicators was, however, experienced somewhat difficult, especially grouping them according to the four viewpoints.

Selecting the indicators became easier when [12] proposed selecting them on strategy basis. In fact, strategy basis can be considered as one of the main characteristics of the second generation balanced scorecard [31]. Another characteristic of the second generation balanced scorecard is the analysis of interrelations reaching individual indicators.

The third generation balanced scorecard differs from the first and second generations, in their development starting from working on organisation's future vision. In addition, distinct development projects are defined and executed to ensure reaching the goals set for the indicators [31].

According to $[20,21]$, one should not accept the performance indicators as given, but the usefulness of each individual indicator ought to be assessed individually. In addition, the performance measurement system development processes are seen important to tailor according to company specific needs. One of the pre-requisites of balanced scorecard to be beneficial is that it replaces, not complement, previous performance indicators [20].

A large number of performance indicators leads into the growth of required workload in utilising the indicators [20]. It may be sensible to aim towards limiting the number of performance indicators, and developing practical guidelines for using balanced scorecard [15]. The literature does describe the aims of balanced scorecard, and the phases for its development and use [23], but does not describe organising the work in practice. Neither does the literature adequately describe potential personnel participation, or utilising the measurement results [20, 22,32].

According to [14] one should pay particular attention to the ease of measurement result availability, reliability of the indicators, acceptability, rapid feedback, and ease of understanding when designing indicators for balanced scorecard. [15] views it important that performance indicators support company strategy and that partial optimisation is avoided. Performance indicators have a connection to a time and place and are not directly transferable from one company to another, and must be changed when the operational environment changes [16]. Objectivity is also important when defining performance indicators, as the subjectivity of these indicators may lead to 
ignoring some indicators and introducing new unofficial ones, or even manipulating the emphasis of the indicators [29].

Employee participation in workplace development processes is seen to enhance employee's working relationships, professional know-how, and commitment [25]. According to [33] the productivity of a Japanese car manufacturer trebled after introducing employee participation in workplace development. In Finland, [34] found indications that management, employees, and specialists taking part in project planning and realisation has a significant connection to productivity and the quality of working life. According to [35] quality improves aside productivity alongside the increase of possibilities for employee participation. Learning at work is also seen as a social process where the organisations task is to arrange an environment that supports employee participation [36].

[37] identified how the start of team work and selfguiding teams, combined with reduced number of hierarchical levels, resulted in a 28 percent productivity increase in German companies. According to [35], changes in the ways of working of an individual employee has minor, or no influence on productivity, while introducing enablers for employee participation results in significant increase in productivity. According to [38] it may be difficult to analyse the impact of individual practices influencing employee participation on productivity, as different practices have a tendency to influence each other, and are rarely used solely.

\section{Research Process}

In this study, first a simplified BSC system was devel- oped by the researchers. After this, simplified performance indicators were designed and trialled in six companies. These six companies were selected so that they would represent typical Finnish SMEs covering different industrial sectors. The simplified BSC includes viewpoints that serve both, the needs of the companies, and personnel. Interviews were arranged to clarify use experiences of the simplified BSC system. This research followed the process illustrated in Figure 1.

Figure 2 illustrates the relation of the viewpoints of balanced scorecard and those used in this study. The selected viewpoints include productivity, safety, and work fluency, all of which are tangible and enable discussions and translating strategy into easily understandable form.

The "economy" viewpoint in balanced scorecard, mostly equals to productivity used in this study. Work fluency can be interpreted as a synonym of "internal processes". Safety covers thorough planning of work and analysing, and eliminating, any deviations in the work processes, and other systematic development of work environment. "Learning and growth" is covered as all the performance indicators during this study were developed using participative approaches. "Customer" viewpoint is not explicitly covered in the three viewpoints. However, if productivity, safety, and work fluency develop positively, it is probable that also customer satisfaction improves.

Each workplace established a working group with the aim of translating the organisation's strategic success factors into a measureable form, so that the success factors could be presented by simple numerical indicators. The underlying idea was that if a workplace wishes to

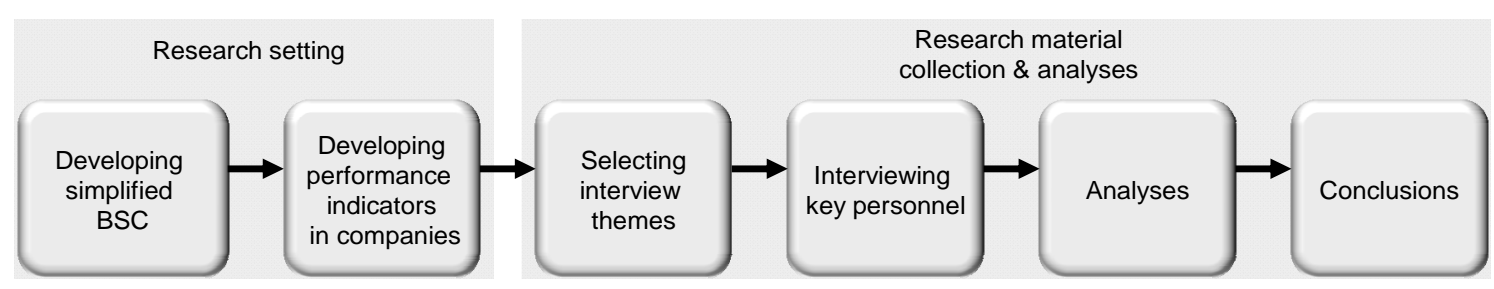

Figure 1. Research process.

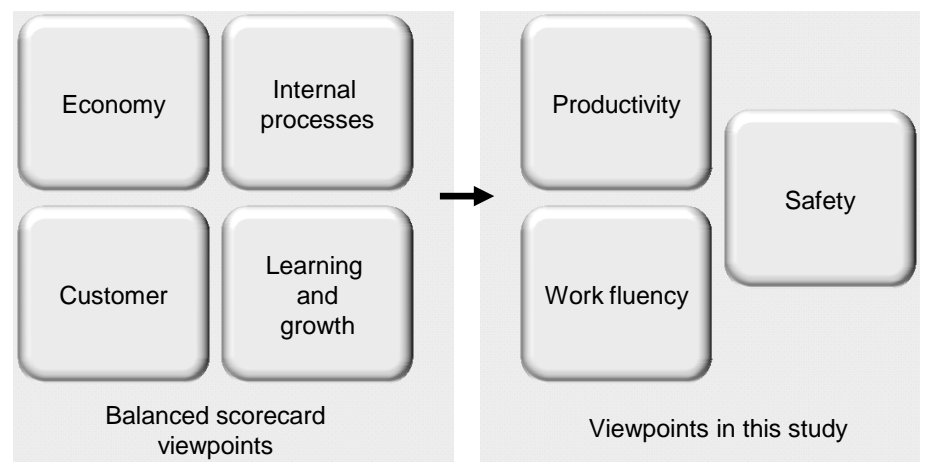

Figure 2. The viewpoints of balanced scorecard and those used in this study. 
develop one of its areas, the state must be possible to monitor via a measureable indicator. Defining the performance indicators enables setting tangible goals for each success factor.

The working groups were formed so that the members had different backgrounds, in terms of education, experience, post, age, sex, and so forth. This desire for variety was to ensure versatility during discussions. Employee representatives were industrial safety delegates, elected officials, or trusted persons representing the employees in some other way. Line management's representations were to ensure that working groups' work and aims would be in line with organisations' strategic goals. The researchers took part in the process mainly by taking care of secretarial duties. The researchers also had a role in activating the discussions, bringing forward new viewpoints, questioning the traditional way of thinking and obtaining background information.

The research material consists of interviews considering the state of the simplified BSCs at six workplaces. In order to obtain as representative sample as possible, workplaces were selected so that they differ from each other by sector, number of employees, degree of automation and/or on risk factors within the working environment. Five of the studied organisations are independent companies, one a laboratory providing services for a large factory. Performance indicators were constructed during two development projects and the interviews were conducted as separate entities, either during the development projects or after them. Table 1 contains information on the studied workplaces.

Workplaces 1 and 2 selected success factors based on discussions between the management and researchers. Workplaces 3, 4, 5, and 6, on the other hand, selected success factors based on discussions among working groups. The working groups utilised viewpoints pre-selected by the researchers, including productivity, safety, and fluency of work. The purpose of the pre-selected viewpoints was to assure equality among different employee groups when defining success factors. The two different ways of selecting success factors resulted in similar results, however, the pre-selected themes speeded the process.

Ten different key people from companies' working groups took part in the semi-structured interviews [39]. The interviewees were selected so that they would represent the views of both, company management and employees. The aim of the interviews was to clarify which aspects ought to be taken into consideration when building and using the simplified BSC. Even though the viewpoints were selected beforehand, the discussions sprawled and went often deeper than anticipated. Selected theses acted as the necessary stimuli for the discussion. More specific questions were presented where
Table 1. Analysed workplaces.

\begin{tabular}{ccccc}
\hline$\#$ & Workplace & $\begin{array}{c}\text { Work group } \\
\text { size }\end{array}$ & Title of the leader & Personnel \\
\hline 1 & $\begin{array}{c}\text { Food processing } \\
\text { plant A }\end{array}$ & 9 & Production manager & 50 \\
2 & $\begin{array}{c}\text { Laboratory } \\
2\end{array}$ & 9 & Laboratory manager & 65 \\
3 & $\begin{array}{c}\text { Industrial service } \\
\text { company }\end{array}$ & 7 & CEO & 113 \\
4 & $\begin{array}{c}\text { ICT component } \\
\text { manufacturer }\end{array}$ & 6 & Technical manager & 60 \\
5 & $\begin{array}{c}\text { Power plant } \\
6\end{array}$ & 5 & Food processing \\
plant B
\end{tabular}

seen necessary by the interviewers. The interview sessions were continued until the emergence of new viewpoints and observations slowed down significantly. The interview material was recorded and transcribed to enable thorough analyses. The content was analysed utilising the principles of content analysis [40]. Appendix A contains excerpts from the interviews.

\section{Results}

\subsection{Workplace Specific Success Factors}

Table 2 illustrates performance indicators derived from workplace specific success factors. Identified success factors differ between the analysed workplaces. Even if the named success factor in two workplaces were the same by title, the indicator derived may be different. For example, the activeness of developing safety issues can be measured by the number of safety initiatives or by monitoring the level of cleanliness and order at the workplace, among any other means, Workplaces 1 and 2 selected their success factors based on the discussions between the management and the researchers. At workplaces $3,4,5$, and 6 the success factors were selected based on the working group discussions by utilising pre-set themes of productivity, safety, and the fluency of work. The pre-set viewpoints aimed to acknowledge the interests of different employee groups, as well as those of employers, while defining success factors. The two seemingly different ways of defining success factors produced relatively similar results. However, utilising the pre-set viewpoints had a tendency of speeding up the process of defining success factors.

The themes selected for interviewing key personnel included developing performance indicators, impacts on productivity, impacts on the quality of working life, and other issues. Each of the themes contained few additional questions to enable focusing. The interviews were recorded and transcribed to enable thorough analyses. 
Table 2. Indicators to follow workplace specific success factors.

\begin{tabular}{|c|c|c|c|}
\hline \# & Workplace & $\begin{array}{l}\text { Experience in utilising } \\
\text { indicators }\end{array}$ & Indicator \\
\hline 1 & Food processing plant A & 4 years & $\begin{array}{l}\text { 1) Point score on a competence map } \\
\text { 2) Workplace order and cleanliness } \\
\text { 3) Number of deviations } \\
\text { 4) Number of customer reclamations }\end{array}$ \\
\hline 2 & Laboratory & 5 years & $\begin{array}{l}\text { 1) Attendance percentage } \\
\text { 2) Share of personnel who have attended work tutor training } \\
\text { 3) Share of personnel who have attended work instructor training }\end{array}$ \\
\hline 3 & Industrial service company & 1.5 years & $\begin{array}{l}\text { 1) Point score on a competence map } \\
\text { 2) Point score average on post-project evaluation form } \\
\text { 3) Number of safety observations }\end{array}$ \\
\hline 4 & ICT component manufacturer & 1.5 years & $\begin{array}{l}\text { 1) Waste } \\
\text { 2) Point score on a competence map } \\
\text { 3) Number of safety initiatives }\end{array}$ \\
\hline 5 & Power plant & 0.5 years & $\begin{array}{l}\text { 1) Workplace order and cleanliness } \\
\text { 2) Boiler specific efficiency }\end{array}$ \\
\hline 6 & Food processing plant $\mathrm{B}$ & 0.5 years & $\begin{array}{l}\text { 1) Workplace order and cleanliness } \\
\text { 2) Daily evaluation of work flow } \\
\text { 3) Number of production interruptions }\end{array}$ \\
\hline
\end{tabular}

During the analyses the material was divided into aspects related to internal communication, personnel participation, and other aspects. These three themes are discussed in more detail below.

\subsection{Internal Communication}

The following aspects were identified as a part of communication:

- Working groups' memos act as a base for discussions

- Performance indicators focus discussion towards aspects important for the company

- Personnel participation while building indicators for success factors improves communication and personnel working relations

- Measuring ought to be linked tightly to company internal communication

According to the interviewed key personnel, memos drafted during working group meetings were important as they initiated discussions also among other personnel. On the other hand, the memos ensured that participants would not forget what was agreed. However, at the same time the interviewed key people emphasised that the memos, or any other company internal documents, alone are not enough. Instead it is vital to raise discussion and provide opportunities for informal face-to-face discussions.

Measuring success factors was seen a medium for raising discussion. A success factor being measured was seen as a permission to bring issues forward in the name of development. This in turn, increased openness at the workplaces and eased making development proposals.

Personnel participation in creating indicators for suc- cess factors was considered as a work mode that improved company internal communication. The interviewed key personnel believed that once an indicator is known, the results will be followed and the results will be attempted to influence by striving towards improvement. The interview participants emphasised how the measurement results must be immediately available for development actions.

It was seen that if the working group participants are enthusiastic about their development work, they will discuss the matter with their close colleagues. This way the information is distributed within organisations, though non-official, but effective channels. Being a part of a working group was seen to improve the working relations of the group participants, further motivating discussions.

It was also seen vital to include the measurement results on success factors into company internal communication. The message must be interesting from the perspective of the recipients' needs. The measurement results act as feedback for employees, providing information how well they do their work in relation to organisations goals. Many of the analysed workplaces, however, viewed informing about the state of success factors still to have some room for improvement.

\subsection{Employee Participation}

The following aspects were identified from the perspective of employee participation:

- The commitment of top management is important

- Building indicators for success factors, and using them, provides employees an avenue for influencing 
developing the company

- Employee participation enhances the development of work environment and eases the launch, and use, of performance indicators

- Taking part in developing the indicators acts as employee training

- External participants lowers the threshold for, and activates, discussion

- Working group remaining the same for extended periods of time is a potential challenge for maintaining the level of fresh ideas

Company top management's participation was considered as a key factor for the success of the working group developing the performance indicators. Managers taking part was seen especially important for speeding up decision making. The selection of working group members was based on management's viewpoints, as well as making any changes to the composition of the group. It was seen favourable for the discussions if managers avoided controlling the discussion excessively and allowed the employees to take an active role in the working group.

The interviewees emphasised that it is vital to have cooperation, and dialogue, between employers and employees while developing indicators for success factors. From the perspective of employee representative, taking part in developing the indicators enables influencing not only the way the indicators are defined, but also how something is measured. This is seen to have an impact on practical solutions in the everyday operations.

The interviewed key people saw the employee participation to provide an opportunity for improving the working environment. In a positive case, being a working group member was a source of pride and improved employee commitment on developing the indicators. This would have a direct positive reflection among the employees outside the working group. Also the launch of a new indicator was assumed to be fluent due to employee participation where as employee needs and viewpoints are already catered for as a starting point.

The interviewed key people also viewed the development of indicators for success factors act as training for the participants. Each group member has to contemplate the success factors in a wider scale, not only from the perspective of their own duties. Considering the company success factors enhances the perspective over the workplace as a system with interacting elements. The versatility among the group members was seen to support the diversity in viewpoints over success factors and on how to measure them. According to the interviews, taking part in the working groups has enhanced then know-how over measuring success factors, and improved the readiness to develop indicators also for other purposes.

The participation of people external to the workplaces, researchers in this case, was seen as beneficial and to make the working more effective. Researchers' questions were seen to activate discussion and enabled realising and question different matters. External viewpoints were seen as valuable, especially when any deficiencies have become so familiar that their existence may not be realised anymore.

Based on the interviews, it seems that a very tight working group is formed around considering success factors. From the perspective of launching and utilising the indicators, it was seen as better if they were based on wide-based employee participation. One possibility for this would be using small temporary working groups. These small groups could be used for problem solving, or realising a partial task that would serve the needs of the official working group. It was seen possible to develop indicators for success factors on one-by-one basis so that the composition of the working group would be different for each indicator based on required specialist knowhow.

\subsection{Other Viewpoints}

In addition to communication and employee participation, also the following other viewpoints were identified among the interview material:

- Measuring the success factors guides the employees' work

- Case specific, small task forces are a way to solve tangible challenges

- Long-term approach is favourable. The aim is that developing indicators evolves from a project to a continuous process

- Working groups had positive indirect impacts on tackling issues external to the scope

- The performance indicators must be developed as the companies evolve

- Developing indicators for success factors improves productivity

The participating key people viewed the measurement of success factors to guide the work of the employees and act as a medium for feedback. From the communication perspective, the indicators were seen important to focus on few of the most important success factors. Also, the indicators were seen important to be easy to understand and unambiguous, in order for them to be effective. The feedback from the indicators is not individualised to point to a single employee, which was seen as an aspect, potentially aiding in rectifying any challenges. The reliability of the results was seen of utmost importance from the perspective of the acceptance of the indicators.

Aside the official working group meetings, the workplaces have had smaller task forces to analyse and solve tangible challenges. These task forces have done pre- 
paratory work for the official working groups. The workplaces viewed smaller assemblies more effective for rectifying any arising issues, instead of wide-based assemblies. In one of the studied companies, regular information and development workshops have been arranged for the entire personnel.

The interviewed key personnel were unanimous on the view that the project of developing indicators ought to evolve into a process and be a part of everyday work. The researcher participation over several years was seen as an engine for positive change.

The working group meetings are seen positive also as they enabled taking care of any minor matters outside the scope of measuring success factors. Many seemingly small matters have enabled improving the fluency of work and enhanced the working environment and reduced employee absence.

The interviewed participants were unanimous on the importance of the indicators evolving alongside the companies. Success factors translating into measurables was experienced as an effective mean for bringing company strategy onto the shop floor as a part of employees' everyday work. Frequent measuring was considered as better from the perspective of feedback. It was seen important to keep any identified issues requiring development on agenda as long as they have been resolved.

Working with the success factors was seen as a way to improve productivity, even if it was difficult to depict the change accurately. The new, more comprehensive understanding over the company functioning was seen as an effective way of improving employee working and know-how. After developing the indicators, there was no need to repeat matters, the work was seen to be better done correctly at once. One of the analysed companies combined the indicators with their bonus system and has reported positive development after few years of launching the programme. Choosing the development focus clearly through defining success factors alone was seen to reduce unnecessary, non-productive work.

\section{Conclusions}

Balanced scorecard is proven a functional tool for companies in implementing their strategy into action. However, small-and medium sized companies have experienced this tool too complicated for their purposes. This research analyses the potential of simplifying balanced scorecard by acknowledging the practical realities of SMEs.

The results of this study indicate that the viewpoints covered by balanced scorecard can be simplified into three categories of productivity, work fluency, and safety. These viewpoints can be presented in such a tangible manner that the personnel of SMEs are capable of com- prehending and discussing relevant matters. This way using a simplified balanced scorecard can aid in taking strategy into the shop floor. Consequently, simplified balanced scorecard can act as a tool for internal communication in SMEs, by converting company strategy into common terms understandable by the employees by directly linking matters into their work reality. Employee participation in developing performance indicators was also seen to act as training for personnel, aside being a key for commitment and success.

The management of small and medium sized enterprises can utilise the results of this study when desiring to boost the implementation of company strategy. Managers should understand that personnel participation in developing simplified balanced scorecard also enhances internal communication and directs discussion into strategic aspects. This study provides a stake in answering the literature's call for describing the process of implementing performance indicators. Also, this study gives an example of simplifying BSC, originally developed for the needs of large corporations, for the needs of SMEs.

The limitations of this study include analysing only a limited number of case companies in Finland only. Further research is required to confirm the results in different types of working cultures and by using a higher number of case companies. It would also be interesting to analyse whether other viewpoints, aside the identified, would be relevant.

\section{REFERENCES}

[1] J.-F. Henri, "Performance Measurement and Organizational Effectiveness: Bridging the Gap,” Managerial Finance, Vol. 30, No. 6, 2004, pp. 93-123. doi:10.1108/03074350410769137

[2] E. G. Flamholtz, T. K. Das and A. S. Tsui, "Toward an Integrative Framework of Organizational Control," Accounting, Organizations and Society, Vol. 10, No. 1, 1985, pp. 35-50. doi:10.1016/0361-3682(85)90030-3

[3] F. W. Taylor, "The Principles of Scientific Management," Harper, New York, 1914.

[4] S. Saari, "Tulosmatriisiohjaus: Ominaisuudet ja Käyttö: Miten Saada Halutut Asiat Tehdyksi Organisaatiossa," Mido Oy, Helsinki, 2004.

[5] Z. J. Radnor and D. Barnes, "Historical Analysis of Performance Measurement and Management in Operations Management," International Journal of Productivity and Performance Management, Vol. 56, No. 5/6, 2007, pp. 384-396. doi:10.1108/17410400710757105

[6] D. J. Fellner and B. Sulzer-Azaroff, "Increasing Industrial Safety Practices and Conditions through Posted Feedback," Journal of Safety Research, Vol. 15, No. 1, 1984, pp. 17-21. doi:10.1016/0022-4375(84)90026-4

[7] J. Komaki, K. D. Barwick and L. R. Scott, "A Behavioral Approach to Occupational Safety: Pinpointing and Reinforcing Safety Performance in a Food Manufacturing Plant," 
Journal of Applied Psychology, Vol. 63, No. 4, 1978, pp. 434-445. doi:10.1037/0021-9010.63.4.434

[8] B. Sulzer-Azaroff, "Behavioral Ecology and Accident Prevention,” Journal of Organizational Behavior Management, Vol. 2, No. 1, 1978, pp. 11-44. doi:10.1300/J075v02n01_02

[9] J. Sinisammal and A. Reiman, "Räätälöity Palautejärjestelmä Työturvallisuuden Kehittämistyökaluna Paperiteollisuudessa-Seurantatutkimus Yhdeksästä Mittaristosta,” Työelämän Tutkimus-Arbetslivsforskning, Vol. 2, 2010, pp.188-195.

[10] K. L. Saarela, “An Intervention Program Utilizing Small Groups: A Comparative Study," Journal of Safety Research, Vol. 21, No. 4, 1990, pp. 149-156. doi:10.1016/0022-4375(90)90022-4

[11] J. Saari and M. Näsänen, “The Effect of Positive Feedback on Industrial Housekeeping and Accidents: A Long Term Study at a Shipyard," International Journal of Industrial Ergonomics, Vol. 4, No. 3, 1989, pp. 201-211. doi:10.1016/0169-8141(89)90003-6

[12] R. S. Kaplan and D. P. Norton, "The Balanced Scorecard: Translating Strategy into Action,” Harvard Business Review Press, Boston, 1996.

[13] J. N. Sorensen, "Safety Culture: A Survey of the State-ofthe-Art," Reliability Engineering \& System Safety, Vol. 76, No. 2, 2002, pp. 189-204. doi:10.1016/S0951-8320(02)00005-4

[14] J. L. Riggs, "The Objective Matrix: A Versatile and Proven Method to Achieve Accountability and Motivation through Productivity Measurement," Proceedings of the 4th World Productivity Congress, Oslo, 13-16 May 1984, $12 \mathrm{p}$.

[15] S. Tangen, "Performance Measurement: From Philosophy to Practice," International Journal of Productivity and Performance Management, Vol. 53, No. 8, 2004, pp. 726737. doi:10.1108/17410400410569134

[16] B. H. Maskell, "Performance Measures for World Class Manufacturing: A Model for American Companies,” Productivity Press, Shelton, 1989.

[17] R. S. Kapla and D. P. Norton, "Putting the Balanced Scorecard to Work,” Harvard Business Review, 1993, pp. 134147.

[18] B. Marr and G. Schiuma, "Business Performance Measurement-Past, Present and Future," Management Decision, Vol. 41, No. 8, 2003, pp. 680-687. doi:10.1108/00251740310496198

[19] A. M. Ghalayini, J. S. Noble and T. J. Crowe, “An Integrated Dynamic Performance Measurement System for Improving Manufacturing Competitiveness,” International Journal of Production Economics, Vol. 48, No. 3, 1997, pp. 207-225. doi:10.1016/S0925-5273(96)00093-X

[20] H. Ahn, "Applying the Balanced Scorecard Concept: An Experience Report,” Long Range Planning, Vol. 34, No. 4, 2001, pp. 441-461. doi:10.1016/S0024-6301(01)00057-7

[21] H. Haapasalo, K. Ingalsuo and T. Lenkkeri, "Linking Strategy into Operational Management: A Survey of BSC Implementation in Finnish Energy Sector,” Benchmark- ing: An International Journal, Vol. 13 No. 6, 2006, pp. 701-717. doi:10.1108/14635770610709068

[22] A. Neely, J. Mills, K. Platts, H. Richards, M. Grogory, M. Bourne and M. Kennerley, "Performance Measurement System Design: Developing and Testing a Process-Based Approach," International Journal of Operations \& Production Management, Vol. 20, No. 10, 2000, pp. 11191145. doi:10.1108/01443570010343708

[23] H. Rantanen, J. Ukko, J. Tenhunen and M. Rehn, “The Implementation of Performance Measurement System in SMEs," Proceedings of ICPR-16, Prague, 29 July-3 August 2001, 17 p.

[24] A. Reiman and S. Väyrynen, "Review of Regional Workplace Development Cases: A Holistic Approach and Proposals for Evaluation and Management," International Journal of Sociotechnology and Knowledge Development, Vol. 3, No. 1, 2011, pp. 55-70. doi:10.4018/jskd.2011010103

[25] J. Wilson, H. Haines and W. Morris, "Participatory Ergonomics,” In: J. R. Wilson and N. Corlet, Eds., Evaluation of Human Work, Taylor \& Francis Group, London, 2005, pp. 933-962. doi:10.1201/9781420055948.ch36

[26] J. Ukko, J. Karhu, S. Pekkola, H. Rantanen and J. Tenhunen, "Suorituskyky Nousuun! Hyödynnä Henkilö-Stösi Osaaminen,” Tykes Raportti 57, Helsinki, 2007.

[27] R. McAdam, "Quality Models in an SME Context: A Critical Perspective Using a Grounded Approach,” International Journal of Quality \& Reliability Management, Vol. 17, No. 3, 2000, pp. 305-323. doi:10.1108/02656710010306166

[28] R. Kaplan and D. P. Norton, "The Balanced ScorecardMeasures That Drive Performance," Harvard Business Review, 1992, pp. 71-79.

[29] C. D. Itther, D. F. Larcker and M. W. Meyer, "Subjectivity and the Weighting of Performance Measures: Evidence from a Balanced Scorecard,” The Accounting Review, Vol. 78, No. 3, 2003, pp. 725-758. doi:10.2308/accr.2003.78.3.725

[30] P. Kujansivu, “Operationalising Intellectual Capital Management: Choosing a Suitable Approach,” Measuring Business Excellence, Vol. 12, No. 2, 2008, pp. 25-37. doi:10.1108/13683040810881171

[31] I. Cobbold and G. Lawrie, "The Development of the Balanced Scorecard as a Strategic Management Tool," Proceedings of the 2002 PMA Conference, Boston, 17-19 July 2002, 9 p.

[32] S. Mooraj, D. Oyon and D. Hostettler, "The Balanced Scorecard: A Necessary Good or an Unnecessary Evil?” European Management Journal, Vol. 17, No. 5, 1999, pp. 481-491. doi:10.1016/S0263-2373(99)00034-1

[33] M. Nagamachi, "Kansei Engineering as a Powerful Consumer-Oriented Technology for Product Development," Applied Ergonomics, Vol. 33, No. 3, 2002, pp. 289-294. doi:10.1016/S0003-6870(02)00019-4

[34] E. Ramstad, “Innovation Generating Model-Simultane Ous Development of Work Organization and Knowledge Infrastructure Experimenting: In the Field of Organizational Development,” Tekes, Helsinki, 2008.

[35] C. Ichniowski, K. Shaw and G. Prennushi, "The Effects 
of Human Resource Management Practices on Productivity: A Study of Steel Finishing Lines," American Economic Review, Vol. 87, No. 3, 1997, pp. 291-313.

[36] P. Tynjälä, "Perspectives into Learning at the Workplace," Educational Research Review, Vol. 3, No. 2, 2008, pp. 130-154. doi:10.1016/j.edurev.2007.12.001

[37] T. Zwick, “Employee Participation and Productivity," Labour Economics, Vol. 11, No. 6, 2004, pp. 715-740. doi:10.1016/j.labeco.2004.02.001

[38] J. T. Delaney and M. A. Huselid, “The Impact of Human

\section{Appendix A-Excerpts from the Interviewees}

\section{Communication}

"The meeting notes raise discussion among the employees.”

"Including an issue in a performance indicator makes it easier to talk about it and also makes it easier to make development proposals.”

"Wide-based personnel participation improves internal communication."

"Once knowing an indicator, one has a tendency to follow them and attempts to influence the results."

"Being a member of a working group can be a source of pride for employees."

"Linking indicators, and measurement results into company communications is important."

\section{Employee Participation}

“Top management participation in the working groups is vitally important."

“A manager playing 'dumb' is one way of activating employees for individual thinking and taking their own initiative."

"This type of exercise of developing performance indicators can only be successful if both, the employer and the employees take an active role."

"Taking part in a working group has somewhat enabled guiding the supervisors' work.”

"Personnel participation improves the working environment."

"Working group participation enables forming new working relationships and makes discussions easier."

"Working group participation has increased the under-
Resource Management Practices on Perceptions of Organisational Performance,” Academy of Management Journal, Vol. 39, No. 4, 1996, pp. 949-969. doi:10.2307/256718

[39] R. Merton, M. Fiske and P. Kendall, "The Focused Interview: A Manual of Problems and Procedures,” 2nd Edition, Free Press, New York, 1990.

[40] J. Tuomi and A. Sarajärvi, "Laadullinen Tutkimus ja Sisällönanalyysi,” Tammi, Jyväskyl, 2009. standing of the workplaces as a whole.”

"The outsider participants in the working groups have enabled finding new viewpoints.”

"The questions presented by the outsiders activate the discussion."

"Participation could be expanded by forming temporary working groups for considering individual issues."

"It is worth utilising the know-how of different people when developing performance indicators.”

\section{Other Viewpoints}

"The three viewpoint approach seems to work well."

"The indicators must be easy to understand."

"Holding company internal meetings between the working group meetings have proved a good practice.”

"Giving homework is a good idea between the working group meetings. The next meeting is a natural deadline for agreed tasks."

"Contemplating any practical matters is good to arrange between the meetings using company internal resources.”

"Developing the indicators can translate from a project into a continuous process, should everything go well."

"Aside developing the indicators, we have rectified many smaller matters as a side product."

"From the perspective of development, measuring often is better than doing it rarely."

"Work environment and the working conditions do have an influence on the quality seen by the customers."

"The influence of the indicators on productivity is challenging to isolate. However, already there are weak signals on the positive influence."

"Learning improves productivity, meaning that one does not need to repeat actions so many times." 